\title{
Engaging an ecovillage and measuring its ecological footprint
}

Article

Accepted Version

Carragher, V. and Peters, M. (2018) Engaging an ecovillage and measuring its ecological footprint. Local Environment, 23 (8). pp. 861-878. ISSN 1354-9839 doi:

https://doi.org/10.1080/13549839.2018.1481021 Available at https://centaur.reading.ac.uk/78936/

It is advisable to refer to the publisher's version if you intend to cite from the work. See Guidance on citing.

Published version at: https://doi.org/10.1080/13549839.2018.1481021

To link to this article DOI: http://dx.doi.org/10.1080/13549839.2018.1481021

Publisher: Routledge

All outputs in CentAUR are protected by Intellectual Property Rights law, including copyright law. Copyright and IPR is retained by the creators or other copyright holders. Terms and conditions for use of this material are defined in the End User Agreement.

\section{www.reading.ac.uk/centaur}

\section{CentAUR}

Central Archive at the University of Reading

Reading's research outputs online 


\section{Cover Page}

Paper title: Engaging an Ecovillage and Measuring its Ecological Footprint

Corresponding Author: Vincent Carragher, Civil, Structural and Environmental Engineering, Trinity College Dublin, Dublin, Ireland. Telephone: 01896 2670. Email: vincent.carragher@tcd.ie.

Co-author: Michael Peters, School of the Built Environment, University of Reading, Reading, UK. Telephone: 0118 3785266. Email: m.d.peters@reading.ac.uk. 


\title{
Engaging an Ecovillage and Measuring its Ecological Footprint Vincent Carragher \& Michael Peters
}

\begin{abstract}
As ecovillages present themselves as models of low-carbon living measuring the Ecological Footprint (EF) of an ecovillage serves both to validate that claim and to examine the component features of how the EF is achieved. This article examines the first measurement of the EF of Ireland's only ecovillage, situated in the village of Cloughjordan in county Tipperary. The objectives here were to measure the EF of the ecovillage at the household scale and then to use the EF to provide meaningful feedback and reflective learning on human carbon intensity to the ecovillage residents. Various methods were applied in this action research to achieve high levels of engagement and potent communication of what could be learnt from the EF. This article places a particular focus on the necessary adaptation of an original EF method, on how it was implemented in the ecovillage, on the results obtained and on how these were communicated to the residents. The bottom-up component EF method samples consumption data at source and in so doing appoints consumption reflection and responsibility in ways the more remote compound method can not. The strategic combination of this specific quality with co-creation method aims to meaningfully engage and motivate a settlement to reduce its carbon intensity. According to the methodology the ecovillage residents overshoot the fair earth share by $10 \%$ needing 1.1 planets to sustain their lifestyles. It is planned that subsequent to this intervention future measurements will show whether the overshoot has reduced.
\end{abstract}

Key words: Ecovillage, Ecological Footprint, Discourse Based Approaches, Cocreation, one planet lifestyle.

\subsection{Introduction}

Measuring the ecological footprint (EF) of settlements has grown in popularity as policy and practice tool in the transition towards a low-carbon society (WWF, 2014; Galli, 2015; Baabou et al., 2017). Wackernagel (1994) originally proposed that quantifying a given population's rate of consumption of natural resources and the impacts of this consumption on natural systems can be a useful means for sustainability 'measurement'. However it is important to recognise that EF 
methods do not attempt to measure the social or economic dimensions of sustainability - they tend to focus exclusively on environmental or ecological aspects (van Vuuren and Bouwman, 2005). Ecological Footprints have been performed at diverse scales from individual consumer products, through cities, regions and countries, to assessing the environmental impact of the world as a whole, and they are predominantly 'compound' in nature (Borucke et al., 2013; WWF, 2014; Galli, 2015; Baabou et al., 2017; Galli et al., 2017). Compound EFs sample aggregated material consumption, at the global, national, regional or city scale, and they follow the early example set by Wackernagel (1994) for Canada. In the view of Castellani and Sala (2013) sustainability indicators can be used to good effect in the promotion of responsibility around consumption practices and this can include household impacts. Wackernagel $(1994, \mathrm{p} 92)$ states that the EF "should help people to realize that sustainability is first of all about one-self, not about what others should do." A meaningful estimation of consumption within human lifestyles is suited to component EFs due to the personal consumption data they require from the consumer (Carragher, 2011). Similarly Sutcliffe et al. (2008) argue that bottom-up or 'component' footprints can help households to take action to reduce their consumption, and Wilson \& Grant (2009) point out that component EFs promote consumption reflection. It has been argued that the component EF method offers significant awareness, education and policy potential in relation to consumption (Kuzyk, 2012; Lin et al., 2013; Liu et al., 2013).

The purpose of this paper is to provide evidence and analysis of this bottom-up EF measurement of an established ecovillage in the Republic of Ireland aimed at 
generating meaningful feedback and reflective learning. This is an avenue of academic inquiry which to date has received little coverage in the growing body of published literature on Ecological Footprinting applications. Global Ecovillage Network work with some 10,000 ecovillages on all continents and determine that, "an ecovillage is an intentional or traditional community using local participatory processes to holistically integrate ecological, economic, social, and cultural dimensions of sustainability in order to regenerate social and natural environments." (GEN, 2018). As ecovillages present themselves as models of lowcarbon living (GEN, 2018; Litfin, 2014), measuring the EF of an ecovillage provides an opportunity to evaluate the extent to which the development is delivering on its promise of sustainable consumption, and to examine component features. This paper examines the measurement of the EF of Ireland's only ecovillage, situated in the village of Cloughjordan in county Tipperary, with a particular focus on the necessary adaptations required to an original EF method, on how it was implemented in the ecovillage, on the results obtained and on how these were communicated to the residents. Lessons for future research together with a series of practical recommendations are provided towards the end of the paper.

\subsection{Case Study: Cloughjordan Ecovillage}

Cloughjordan Ecovillage is built on a 27 hectares site behind the main street of the village of Cloughjordan. With a planned 130 residential units and the completion of infrastructure works in 2008 , the first houses were constructed in 2009 and the ecovillage's first residents moved in during December 2009. By 2015, 85 building sites had been sold and 55 housing units were built containing 
approximately 140 residents. The residential area comprises one-third of the site. A further one-third is devoted to support services and amenities including a district heating (DH) system, an eco-enterprise centre, allotments for growing food and a community farm. The final third is devoted to woodland in which 17,000 trees were planted in 2011, with mainly indigenous species. The 49-page 'Village Ecological Charter' encompasses a set of agreed sustainability standards and the means to achieve them approved by ecovillage residents and binding on them (SPIL, 2007). This states that the primary objective of the ecovillage "is to demonstrate truly sustainable development, in as holistic a way as practicable, in order to serve as a model and an educational resource for Ireland" (SPIL, 2007: p.11).

Five of the founding ecovillage members were surveyed at the design stage of the ecovillage, and projections of its sustainability gathered (Ryan, 2003) prior to development work. Since residents began living in the ecovillage, there had been an interest in compiling data to provide a baseline measure of its environmental sustainability.

\subsection{Structure of the paper}

The paper follows on from this introduction with a methods section which underlines the origin of the methodology, and details its adaptations and its development. This includes discussion of challenges encountered and how these were resolved. The results section follows, with thematic presentation and analytical discussion of survey data contextualized relative to the ecovillage's demographic composition. This includes key findings emerging from the EF 
results. The final section draws the paper together with conclusions and recommendations arising from the EF work undertaken in the present study.

\subsection{Methods}

The initiative to measure the ecovillage's ecological footprint utilises EF research including that conducted by the Centre for Environmental Research in the University of Limerick and leverages the engagement of VERT, the (eco) Village Education, Research and Training group. The mixed research approaches included Material Flow Analysis, Ecological Footprinting, Surveying, Discourse Based Approaches (DBA) and Communication. The aim was to co-design with, the methods adopted, as much as possible in generating the ecovillage EF. It was also to foster conversation reinterpreting the EF results to co-produce local lowcarbon messages and advice. The co-creation approach used combines these codesign and co-production elements. A summary of key components relevant to the results presented in this paper are now described. See Carragher (2011) for a more detailed treatment of the original methodologies used as these are not the focus of this paper.

\subsection{Measuring the ecological footprint}

Material Consumption analysts in the Centre for Environmental Research (CER) at the University of Limerick have built EF survey methods based on the component and compound EF approaches for Irish settlements (Carragher, 2011; Ryan, 2006; Foley, 2006). The EF research of Carragher (2011) specifically aims to utilise material consumption data at the household scale and reaches further than the compound $\mathrm{EF}$ in that it points worthwhile attention on 
consumption reflection and responsibility. It was based on the previous EF research of Wackernagel (1994), Hakanen (2001), Barrett et al. (2002), Aall \& Noorland (2002), Chambers et al. (2004), Ryan (2004), Foley (2006) and Ryan (2006). It built a specific component EF method for measuring the ecological footprint of Irish settlements and explored material consumption on a longitudinal (with annual EF measurement followed by low carbon focus groups conducted over four years) as opposed to the conventional one-off or cross sectional time scale (Carragher, 2011). This original bottom-up method was tested in Ballina, a settlement in County Tipperary, and subsequently on a number of other Irish communities. Results of the method's impact on the lowcarbon transition of Ballina, which included a $28 \%$ reduction in EF and emissions over 4 years, can be found in Carragher (2011). As ecovillage residents wished to use the EF measurement and its feedback to educate their consumption reflection iteratively it was decided to use and adapt this original method.

The scope of the EF was to include the impact of the domestic lifestyles of the ecovillage residents. Compiling the EF necessitated quantities of material flows through each household and therefore required residents to report their energy consumption, waste assimilation, food consumption, water consumption, built land area and travel practices. A questionnaire (a copy of which is provided in the Appendix) was distributed to all households in the ecovillage with questions structured around the following issues:

- Household characteristics (number of dwellers; size and type of house);

- Household energy use and its sources;

- Household waste (landfill, recycled and composted); 
- Food consumption and its origin;

- Transport (modes - car, train, bus, air, bike, walking - and frequency);

- Water use, including water-saving measures and water harvesting.

In order to generate an EF the material flows (related to household energy consumption, waste assimilation, food consumption, built land area, water consumption and travel practices) need conversion to appropriated land use as per the calculation:

$$
\begin{gathered}
\mathrm{i}=\mathrm{n} \\
\mathrm{EF}_{1}=\sum(\mathrm{D}+\mathrm{N})
\end{gathered}
$$

$\mathrm{i}=1$

where $\quad \mathrm{EF}=$ total ecological footprint of a locality, $\mathrm{l}$,

$\mathrm{D}=$ direct land use,

$\mathrm{N}=$ additional land requirement (notional energy land),

$\mathrm{i}=$ represents the number of component parts to the footprint.

(Barrett et al., 2004).

The calculation depicts inclusion of 'energy land' and direct land use within the EF. In relation to energy land the material flows provided in the completed questionnaires were converted into embodied energy values and afterwards into related emissions using $\mathrm{CO}_{2}$ conversion factors. Sequestration and equivalence factors allowed conversion of the latter into land areas. In relation to land use the material flows as revealed in the questionnaire were converted into land areas using established yield factors and equivalence factors. Equivalence factors are 
necessary to normalise the distribution of global hectares in order that they equal the number of actual hectares of bioproductive land and sea (Birch et al., 2004).

Widely recognised challenges for research in ecological footprinting include inter alia: (i) a lack of standardisation; (ii) its static nature; (iii) clear definition of system boundaries; (iv) relatively large standard error; (iv) data gaps; and (v) its clear focus on just one human impact, that is $\mathrm{CO}_{2}$ emissions (GFNSC, 2009). The method used here has been tested in the context of other communities and is used in a comparative/relative sense allowing for measurement, benchmarking, feedback, reflection and comparison to occur over a longitudinal time horizon. While standardisation of compound methods has been more successful these reasons mitigate against the problems associated with standardisation of the component EF used here. The longitudinal method involved iterations enabling the generation of 'snapshots' of the ecovillage EF and comparisons across time so this is far from a one-off static measure. There are clear definitions of the scope of this EF method which have already been discussed and which aim to provide a tool and a process which is as informative as possible to the residents. The standard error is a concern for any measurement that is cross-sectional in nature but due to the relative and longitudinal measurement it is not considered as an especially major issue in this study. Furthermore it is not claimed that each EF measurement is a purely accurate metric but more that it allows relative benchmarking, discussion, education and reflection. The majority of the data was acquired at the household level for this EF and where gaps exist national data have been utilised as a proxy, thus reducing problems associated with data gaps. 
The last key challenge for the EFs referred to above is the singular human impact which EFs measure, namely $\mathrm{CO}_{2}$ emissions. This is at best a contested point as the EF tracks multiple human demands on the biosphere not only that placed by carbon (Borucke et al., 2013). This EF method also encompasses methane emissions and so measures that portion of human impact associated with $\mathrm{CO}_{2}$ and $\mathrm{CH}_{4}$ emissions at the household scale. This is highly relevant given the commitment of the residents to a low-carbon transition. In summary the EF applied on a longitudinal scale provides, inter alia, a useful relative measure of low carbon transition at the community level.

In order to provide clarity on responsibility for consumption this EF method uses locally derived household consumption data wherever possible. The EF method required survey query of the resource consumption data as defined in Table 1.

\section{Table 1: Sources and metrics of resource components}

Missing from Table 1 is the Built-land area component of the EF which relates to the land used by human buildings and infrastructure. The Cloughjordan ecovillage project has however dedicated twice the built land area to biodiversity and food productivity and it is posited that this more than compensates for the built-land area impacts. Its buildings have different and lower embodied energies to more conventional settlements and their composition varies widely within the ecovillage making their calculation complex. Further to this the previous calculated built land area EFs, of conventional build settlements, were a minor component of the total EF (Carragher, 2011) and it was thought that the 
omission of built-land would initially allow the intervention to focus on more carbon intense areas for improvement. Having said this, the built-land characteristics of each home and the ecovillage site were calculated and it is planned that their built land EF will be included in future EF measurements.

\subsubsection{Converting material flows to ecological footprint}

Conversion of all material flows in Table 1 into equivalent EFs was examined in the original method by Carragher (2011). Transport practices, food consumption, household energy consumption and waste assimilation have numerous subcomponents and space here is restricted. For this reason we provide one example of converting consumed resources into the equivalent EF for bottled gas. Energy densities and conversion factors for each energy source used in the ecovillage were checked and updated where necessary and this is reported on later in this paper.

Surveillance of bottled gas with local retailers showed the local commercially available bottles contained $11.4 \mathrm{~kg}$ of LPG. The energy density of LPG is 13.1 $\mathrm{kWh} / \mathrm{kg}$ (SEAI, 2015a) while the SEAI conversion factor for LPG is $229 \mathrm{~g}$ $\mathrm{CO}_{2} / \mathrm{kWh}$ (SEAI, 2015b). Line 1 in Table 2 converts annual gas consumed to its related carbon dioxide $\left(\mathrm{tCO}_{2}\right)$ emissions. Line 2 then takes this annual emissions figure and converts using a WWF type analysis to related Ecological Footprint. Firstly 3.66 translates the amount of $\mathrm{CO}_{2}$ emitted to the equivalent amount of carbon. Subsequently the global average for carbon sequestration per hectare of forest land (0.95t C per ha/year) was applied (Chambers et al., 2004). Hectares of forest were then converted to global hectares of global average productivity 
applying the equivalence factor 1.35 (WWF, 2005). And finally allowance for the percentage of $\mathrm{CO}_{2}$ absorbed by oceans (31\%) was also made (WWF, 2005,). The product of line 2 provides the annual EF related to bottled gas consumption and this type of calculation was completed for each material flow within each household as per Carragher (2011).

Table 2: Conversions for bottled gas-use and its related EF

\subsection{Initiating procedures and engagement with the ecovillage residents}

To avoid the poor response to conventional intervention campaigns such as the Power of One (ESRI, 2013), establishing trust and ownership of the community endeavour is acknowledged to be a key to success in low-carbon transition (Carragher et al., 2018). Action Research methods which are face-to-face and bilateral enable data acquisition from research subjects and provide substantial participation and engagement potential for communities (Beckley et al., 2006; Slocum, 2003). These methods support a two-way flow of information leading to co-creation, and establishment of trust, and ownership (Carragher et al., 2018).

Initially the Cloughjordan ecovillage and its Community Based Organisations and other stakeholders were profiled using surveillance, collaborative and desktop review type method. In this way contacts and synergies were identified locally. Having identified and approached a number of these it was decided that VERT (Village Education, Research and Training group) was the natural synergistic entity to invite for participation in the initial EF survey. VERT aims to support education in sustainability of ecovillage residents as well as attempting to reach 
and influence citizens in the wider society. Strong drivers for VERT and for this research were the internal benchmarking of the EF of the ecovillage, dissemination of related learning internally and dissemination of low-carbon case studies and example to society at large. Based on this initial profiling, the EF intervention was well supported by contacts and stakeholders within the ecovillage.

The survey method largely offered streamlined replication as it had been tested on a number of Irish communities. A number of challenges were however encountered in aligning the survey method and its calculations to the specific consumption practices of the ecovillage. Questions and calculations needed to be customised in order to capture the relatively low consumption levels, emissions and footprint of many of those in the ecovillage. Initial surveillance and collaboration with the VERT group and appraisal of the ecovillage Charter were undeniably essential steps in identifying necessary adaptations, both to calculations and to the original questionnaire.

\subsubsection{Organisational Workshop}

After initial meetings with VERT it was decided to host a co-design workshop

with their members in order to enhance engagement and procedural justice. The Workshop Plan (guide) involved briefing VERT on the EF survey process and provided a visioning exercise for the implementation of the EF survey. It gave VERT an opportunity to query the specific activities required to achieve their EF survey objectives within a given time frame. The main distinction between a workshop and other DBA, is that participants are expected to work together to 
achieve outcomes (Beckley et al., 2006). Co-design was achieved through VERT providing on-the-ground knowledge as to how the EF survey could most effectively be administered while the facilitator provided knowhow of the EF measurement method, the EF surveying procedure and post EF survey feedback methods. Through the workshop discussions VERT became significantly involved in the EF survey process and organised a pilot survey and a community-wide EF launch event subsequently. They also volunteered to distribute the final EF questionnaire, to manage dissemination surrounding the EF intervention and to organise post EF measurement feedback to the community. Further to this, VERT acted as a trusted physical presence in the ecovillage where completed questionnaires could be lodged. It also provided environmental champions who supported the EF survey's implementation throughout making the collaboration

more flexible and fluid. The survey was piloted in March 2014 prior to finalisation in order to customise its probing appropriately to consumption practice in the ecovillage.

A launch session was organised in the ecovillage in April 2014 where the EF method was outlined alongside its synergies with the ecovillage and its potential benefits. This involved 25 ecovillage residents.

\subsubsection{Material flow data, focus group and personalized audit}

The questionnaire was distributed to each ecovillage householder who was requested to complete and return within a fortnight. One of the major advantages of the self-report format is that "the respondent does not have to admit directly to an interviewer a socially undesirable or negatively valued 
characteristic" (Fowler, 2014). Other benefits can include accurate sampling, a minimum of interviewer bias, and a degree of personal contact (Oppenheim, 2000). Ryan (2004) states that the key to gaining reliable consumption estimates is to relate "the consumption of an item to a measurable construct" ensuring the respondent is not guessing or indicating preferred consumption levels. An example here is that waste production estimates were produced by querying waste bin size and fullness or bags of waste produced weekly. This weekly metric can be provided more reliably by the householder than an annual or even monthly equivalent.

Given the complexity of material flows within the household, it was recognized that completion fatigue could reduce recovery rates (as discussed in Carragher, 2011). In order to facilitate residents in completing and returning questionnaires VERT volunteers distributed them to households providing multiple chances for completion and collection. The recruitment of these volunteers (environmental champions) was a considerable benefit here as trust was implicit and anonymity guaranteed.

Subsequent to EF measurement a focus group was convened in November 2014, bringing together residents and groups to discuss perspectives and experiences on their carbon transitions. This type of Participatory Action Research acknowledges the importance of integrating local narrative and reinterpretation (Satterfield et al., 2000) and Lejano et al., 2013) and enhances procedural justice in low-carbon transition (Carragher et al., 2018). A pre-focus group planning session with VERT members was organised where the results of the EF were 
presented and approaches for communication and sharing of the information were discussed and co-designed. In the focus group the results of the EF were shared with the audience by the facilitator who then offered the discussion to the audience providing appropriate space for reinterpretation and co-production of low-carbon ideas. Given the interests and motivation to live in the ecovillage many residents provided practical ideas to reduce the carbon intensity of local behaviour and practice. As well as residents, ecovillage group members of VERT and FEASTA (an environmental NGO headquartered in the ecovillage) were probed for relevant information co-producing an internal trusted message as opposed to an external one. Potent communication was maximised by making sure that the low-carbon message was kept as local as possible.

After the Focus Group the author compiled the EF of 18 individual households and these were posted to residents in August 2015. In relation to the literature on social acceptance, trust and participation every effort was made to maximise procedural and distributional justice for the ecovillage residents - particularly through the extensive emphasis on practical inclusion and engagement of the residents themselves.

\subsection{Results and Discussion}

\subsection{Survey Recovery and Demographic Characteristics}

Survey completion was voluntary and at the time of distribution there were 50 occupied houses in the ecovillage. Forty-seven of the households completed the questionnaires and all were usable. Despite the option to remain anonymous 44 
of the 47 households identified themselves. Eighteen (38\%) of the 47 householders paid a modest fee for an individual EF to be completed relating to their indicidual household's consumption. These aimed to deepen the consumption reflection and responsibility already attained, thus potentially deepening the communication channels further. Overall a 94\% recovery rate was achieved - arguably indicative of the residents' commitment and drive regarding the realisation of a low-carbon transition (and pointing to validation of the forecast benefits of the methods employed regarding trust, participation, ownership, and tangible delivery of procedural and distributional justice).

\section{Table 3: Queried demographic characteristics of the ecovillage}

Table 3 shows that the predominant house type (53\%) in the ecovillage is detached (compared with a national average of 43\%, SEAI, 2008). Though this national average predates this research, little housebuilding has taken place in Ireland since this date due to the recession. Less than $10 \%$ of built ecovillage houses were apartments, roughly equivalent to the national average and similar proportions were found to be live and work units. Approximately $18 \%$ of Irish homes are terraced while $27 \%$ are semi-detached (SEAI, 2008) and these are greater proportions than for the ecovillage equivalents where $20 \%$ of the built homes are semi-detached and 5 (11\%) are terraced houses (Table 3). Four residents (less than 10\%) live in residences of $99 \mathrm{~m}^{2}$ or under, $17(36 \%)$ are between $100-149 \mathrm{~m}^{2}, 9(19 \%)$ are $150-199 \mathrm{~m}^{2}, 11$ residences were reported to be 200-249 $\mathrm{m}^{2}$ and one was $250-299 \mathrm{~m}^{2}$ (Table 3). On average houses were built in 2011 in the ecovillage when the national average for floorspace was $187 \mathrm{~m}^{2}$ per 
household (CSO, 2011) while that for the houses in the ecovillage was $166 \mathrm{~m}^{2}$ showing that homes were being built $11 \%$ smaller in the ecovillage reducing embodied resource use and operational resource use. The houses built in the ecovillage have enabled substantially increased energy efficiency in comparison to the average Irish household (McLoughlin, 2015). Measures such as the higher insulation and ventilation standards and lower average floor areas of the ecovillage households counteracts their larger surface area.

The average number of storeys in the ecovillage households is 2.4 , with average occupancy per household of 2.2 and their average number of children attending school 0.6 (Table 3). Occupancy is lower than the national average and the North Tipperary average as defined by Census (CSO, 2011) both of which were 2.7.

\subsection{EF Questionnaire and calculation adaptations}

Surveillance and profiling of the available services, discussion with VERT and the pilot survey allowed adaptations of the method to the consumption practices prevalent within the ecovillage. Adaptations adopted are detailed here:

1. Actual annual District Heating (DH) energy use (kWh) and water use (L) were supplied by VERT for each household and entered into the EF questionnaire prior to household distribution, increasing accuracy and reducing completion difficulty, time and potential fatigue;

2. Questionnaire to include for, and to query, the ecovillage practice of sharing waste bins between households;

3. Local recycling destinations were included;

4. House sizes were queried in metric measurements; 
5. Travelling distances were queried by the month and not as previously by week;

6. Car and journey sharing were distinguished and queried;

7. Due to the absence of adequate information for direct and indirect impacts of DH emissions, these were assumed to be zero;

8. As there are diverse methods for discounting the emissions of electricity, provided by green suppliers, no discount was to be provided;

9. The original method utilised embodied energies of the food items in the average Irish diet to calculate a food EF. The ecovillage diet comprises substantial differences to that of the average Irish citizen as it includes amounts of organic, local or self-grown food. It was decided to query this information so that when a method became available at a later stage it could be used to calculate these differences more exactly.

Examples for the material flows relevant to the ecovillage of food, waste, water, electricity, bottled gas, briquettes and wood are reviewed in Carragher (2011). The following update of conversion factors was necessary:

1. Calculation of the 2014 electricity emissions factor using the Eirgrid website's 15 minute emissions data for that year (calculated at $0.451 \mathrm{~kg}$ $\mathrm{CO}_{2} / \mathrm{kWh}$; Eirgrid (2016));

2. Emissions factors for car transport were based on the DEFRA average of 0.19445 kg CO2 pkm DEFRA (2012);

3. Average local bus emissions per passenger kilometre of $0.14754 \mathrm{~kg} \mathrm{CO} 2$ were based on DEFRA (2011);

4. Emissions factors of $0.0582 \mathrm{~kg} \mathrm{CO} 2$ per pkm (train), $0.091 \mathrm{~kg} \mathrm{CO} 2 / \mathrm{pkm}$ 
(short haul air travel) and $0.109 \mathrm{~kg} \mathrm{CO} 2 / \mathrm{pkm}$ (long haul air travel) were based on DEFRA (2012);

5. Water data from the Cloughjordan pumping and water treatment station were acquired where annual estimates of $400 \mathrm{kWh} /$ megalitre were used to calculate the energy requirements of water provision to each household;

6. The conversion of embodied energy of food, water and waste to related emissions used the emissions factor calculated above $\left(0.451 \mathrm{~kg} \mathrm{CO}_{2} / \mathrm{kwh}\right)$.

\subsection{Ecovillage Ecological Footprint}

An EF of 2.03 global hectares (gha) was estimated as the average EF of an ecovillage resident. This is the lowest recorded for an Irish settlement (Carragher, 2011 and Carragher et al., 2018). Globally, it is estimated that the maximum EF for each human, that allows them live within the planet's biocapacity, is 1.80 gha (WWF, 2014). Based on this, the ecovillage residents require 1.1 planets to support their domestic lifestyles defining a $10 \%$ overshoot.

The EF design estimate (Ryan, 2003) for the ecovillage, using the forecasts of five founder residents, of 1.95 gha proves to be $4 \%$ lower than the average ecovillage EF of 2.03 gha revealed in the research reported in this paper. Additonally it is interesting to note that Foley (2006) did not include built land, air or public transport impacts in his EF evaluations, yet his Ballina EF estimate was $10 \%$ lower than that calculated by Carragher (2011) corrected for air transport and built land. The methods and techniques employed both by Ryan (2004) and Foley (2006) had a major influence on the methodological development of 
Carragher (2011). And although these component EF methods are not identical, we argue that they are broadly comparable. Clearly the 2.03 gha is low compared to an average EF of 4.35 gha for 79 Irish settlements taken from research by Foley (2006). Effectively 4.35 gha is a slightly conservative estimate for the EF of 79 Irish settlements and though not strictly comparable further emphasizes the reported low material resource use in the ecovillage. The 2.03 gha also compares extremely well to the EF of 2.93 gha which was achieved after a four-year low carbon intervention (Carragher, 2011). One can see that after a four-year lowcarbon intervention on this settlement its EF was still $45 \%$ above that of the average ecovillage resident. There are two caveats here: (i) it could be argued that the Irish recession placed a downward pressure on the average ecovillage resident's EF as this is the chief impact which the varying temporal scale might induce; and (ii) the studies referred to have used reported material flows attained using questionnaires - which, for well acknowledged reasons - may have led to the formation of a consumption scenario that is not entirely factually accurate (for a more detailed treatment of this problem see Carragher, 2011 and Carragher et al., 2018).

\subsubsection{Ecological footprint for energy}

Figure 1 shows that the energy EF for the average ecovillage resident is significantly lower than that in the other settlements; and it is 6.5 times lower than the average of the 79 Irish settlements. A large part of this is the infrastructural impact of the wood chip District Heating (DH) system in the ecovillage. Comparing the average Irish electricity consumption per person in 2011 (SEAI, 2013) of $1815 \mathrm{kWh}$ and its EF of 0.22 gha to the ecovillage resident 
electricity EF of 0.15 gha shows the former to be $48 \%$ larger than that in the ecovillage. Again at least part of the reason for this is technology as each of the ecovillage houses has LED lights and high efficiency appliances.

\subsubsection{Ecological footprint for waste}

Again one can see that the waste EF of the average resident of the 79 Irish settlements at 0.89 gha was 2.8 times larger than that of the ecovillage resident at 0.32 gha. Waste assimilation practices within the ecovillage include significant composting and recycling while landfill volumes are often low as bin sharing between households is common.

\section{Figure 1: EF and its components for Irish settlements}

\subsubsection{Ecological footprint for food}

The food EF of the average resident in the 79 Irish settlements was 2.08 gha and this is 2.3 times larger than that for the average ecovillage resident. The chief input probed by the questionnaire to calculate the food EF is the proportion (by weight) of vegetarian and fruit diet to animal diet and so it is clear that the ecovillage residents eat considerably more vegetable and fruit-based diets on average, thus reducing related emissions considerably. Other factors such as their local self-generated farm produce, their practice of permaculture, residents' self-growing on the provided allotments and their purchase of local food need to be factored into the method in order to further discount the carbon intensity of their food production and consumption practices. This is a complex matter and the aim is to include these practices in later editions of the ecovillage EF. It is 
clear though that the average ecovillage food EF is below the 0.90 gha calculated here.

\subsubsection{Ecological footprint for transport}

The transport EF of 79 Irish settlements of 0.36 gha includes only the motor car impacts of travel and is $9 \%$ higher than that of the average ecovillage resident (0.33 gha). Ballina is largely a commuter settlement and its transport EF (bus, train and car) prior to its four-year low-carbon intervention was 0.65 gha or 1.7 times larger than that for the average ecovillage resident. After the four years this reduced as can be seen in Figure 1 to 0.46 gha or $23 \%$ above that of the average ecovillage resident. The ecovillage car transport-related EF is decreased inter alia due to (i) the presence of a car club in which three cars are shared between 10 houses; (ii) shared journeys; and (iii) due to some householders not owning a car. Despite this, many of the residents travel a distance for their professional careers and this increases the car transport-related EF close to that of the 79 settlements. The air travel impacts of the average ecovillage resident can be seen as higher than that of the Ballina residents both prior to their campaign in 2005 and subsequent to it in 2008. The method conservatively measures the EF of air travel (as explained in detail in Carragher, 2011). The average ecovillage air travel EF is $48 \%$ larger than that of the average Ballina resident in 2008 and $23 \%$ above the equivalent 2005 figure. This shows that ecovillage residents take more flights on average than the commuter settlement of Ballina which has a relatively high professional cohort as does the ecovillage.

\subsubsection{Ecological footprint for water}


The water EF for all settlements considered is relatively small and factors in the energy consequences of water pumping and treatment only. Having said this the water EF of the average Ballina resident was found to be 6 times larger than that for the average ecovillage resident.

\subsection{Focus Group}

The discourse based approach and ecological footprint method in tandem have enabled this research to explore current consumption practices in some depth. An example is where the completed questionnaires highlighted that just $21 \%$ of the ecovillage residents owned a microwave. Other observers have estimated that $86 \%$ of Irish households own one (Leahy and Lyons, 2009). Given their high efficiency and emissions reduction capacity one might expect greater ownership of microwaves in the ecovillage. The facilitator queried this in the focus group and the consensus was that ecovillage residents preferred to cook with a more "natural" cooking device and were unsure about the health benefits of using a microwave. This decision not to use microwaves shows a clear dissonance amongst the ecovillage residents between environmental benefits and purchasing this type of appliance that could have the potential to contribute to lowering their electricity consumption.

Another example of the benefits of exploration offered by DBA and EF approaches is that the research methods here have also identified the lowemissions car and waste-bin sharing practices of the residents and these represent real possibilities for other citizens and society more generally. 


\section{Figure 2: Variance of consumption practice in Cloughjordan ecovillage}

The variance in all the consumption categories measured is large and Figure 2 shows this benefit of the EF as a communication tool where residents with low waste footprints can share their knowledge and practice (co-produce) with those with higher footprints. Using the DBA the author communicated the diversity of consumption at the focus group, showing slides similar to Figure 2 and by then promoting significant discourse in waste EF reduction. Similar facilitated conversations took place for each material flow. Residents proficient in each area were encouraged to share their practices and points of view, thus building a shared local knowledge and capacity on each issue. Figure 2 and its reinterpretation using DBA further underlines the benefits of such co-creation research and intervention.

It is hoped that future measurement of the ecovillage EF by the author will reiterate the benefits still further. Through co-design of the intervention, it is the aim of the author and VERT to co-produce case studies of transferrable lowemissions practices within the ecovillage and communicate these to society at large.

\subsection{Conclusions}

In general the ecovillage households had less occupants, were smaller, and more efficient than is the norm in Ireland. Factors which can drive ownership in lowcarbon endeavour are local and meaningful measurement, stakeholder identification, characterisation, early recruitment, engagement, knowledge 
generation, local narrative, bridging organisations, co-creation and DBAs. These factors were applied in this action research and achieved high engagement and ownership levels within the ecovillage settlement. The profiling, identification and recruitment of synergetic groups, together with the EF as a communication tool and skilled facilitation, allowed local, scientific and meaningful knowledge to be trusted and shared within the settlement. The DBA allied to EF measurement will be utilised in further work with the ecovillage maintaining iterative EF measurement followed by carbon responsibility and reflective Focus Groups.

The recovery rates achieved indicate that the component based bottom-up EF allied to co-creation method, presents opportunities to generate ownership and drive sustainability transition, not present with top-down compound EFs. Further EF measurements in the ecovillage over the next number of years will ascertain this more definitively.

The component EF measurement and its variations (Figure 2) offer strong learning potential both within and outside the ecovillage in relation to reducing the carbon intensity of society and its citizens. In tandem with DBAs it also highlights the complexity of low-carbon transition and why methods need to be carefully chosen to guide sustainability at the local level.

Research interventions including audits and information feedback have produced significant savings such as those in a sustained longitudinal study of $28 \%$. This said infrastructure can play a really important part in lowering carbon intensity and this was identified by the energy EF results. The difference the DH 
system in Cloughjordan made to the related energy EF was so substantial that it provides an important message for policy makers in their attempts to lower the environmental impacts of local communities, settlements and regions.

A standardised approach for the EF has not been achieved at the component level. One of the most important elements of the EF measurement in this research is its longitudinal application. And though the absolute value is important the relative metric over various time horizons is a more salient feature and contributes substantially to the potent feedback communication required for such interventions. It is planned to repeat the method used here, to measure the EF of the ecovillage, through which a relative measure and a measure of transition is attained. As discussed earlier, further modification to the method in relation to built area, food consumption and DH evaluation would provide stronger insight in time to come.

Adapting the EF method of Carragher (2011) shows the ecovillage residents overshoot the fair earth share by $10 \%$ needing 1.1 planets to sustain their lifestyles. Future measurements will need to be undertaken and presented in order to identify and demonstrate the extent to which the overshoot has been managed.

\section{Acknowledgments}

This research was part supported by NWE Interreg IVB through the Academy of Champions of Energy project [228H]. Specific detail was received from Tipperary Energy Agency staff namely PJ McLoughlin and Enda McGovern. Appreciation for 
the collaboration of VERT members is noted specifically Duncan Stewart, Davie

Philip, Peadar Kirby and most especially Deirdre O’Brolchain.

\section{References}

Aall, C. and Norland, I.T., 2002. The Ecological Footprint of the City of Oslo; Results and Proposals for the Use of the Ecological Footprint in Local Environmental Policy. Program for Research and Documentation for a Sustainable Society (Oslo).

Baabou, W., Grunewald, N., Ouellet-Plamondon, C., Gressot, M., Galli, A., 2017. The Ecological Footprint of Mediterranean Cities: Awareness Creation and Policy Implications. Environmental Science \& Policy, 69, 94-104.

Barrett, J., Vallack, H., Jones, A., and Haq, G., 2002. A Material Flow Analysis and Ecological Footprint of York; Technical Report. Stockholm Environment Institute (York).

Barrett, J., Cherrett, N., Hutchinson, N., Jones, A., Ravetz, J, Vallack, H. and Weidmann, T., 2004. A Material Flow Analysis and Ecological Footprint of the South East-Project Report, Taking Stock, Managing our impact. Biffaward (UK).

Beckley, T.M., Parkins, J.R. and Sheppard, R.J., 2006. Public Participation in Sustainable Forest Management: A Reference Guide. Sustainable Forest Management Network (Canada).

Birch, R., Barrett, J. and Wiedmann, T., 2004. Ecological Footprint of Inverness. Stockholm Environment Institute (York).

Borucke, M., Moore, D., Cranston, G., Gracey, K., Iha, K., Larson, J., Lazarus, E., Morales, J.C., Wackernagel, M., \& Galli, A., 2013. Accounting for demand and supply of the biosphere's regenerative capacity: The National Footprint Accounts' underlying methodology and framework. Ecological Indicators, 24, 518-533.

Carragher V., 2011. Using and Ecological Footprint to operate and maintain a short-term self-regulating and community-based Environmental Programme. $\mathrm{PhD}$ Thesis: College of Science, University of Limerick (Limerick). Available at http://ulir.ul.ie/bitstream/handle/10344/1955/2011_Carragher\%2c\%20Vince nt.pdf?sequence $=6$. Last accessed $9^{\text {th }}$ April 2018.

Carragher, V., O’Regan, B., Peters, M. \& Moles, 2018. Novel resource saving interventions: the case of modelling and storytelling. Local Environment, 23, 5, 518-535.

Castellani, V. and Sala, S., 2013. Sustainability Indicators Integrating Consumption Patterns in Strategic Environmental Assessment for Urban Planning. Sustainability, 5, 3426-3446.

Chambers, N., Griffiths, P., Lewis, K. and Jenkin, N., 2004. Scotland's Footprint. Bestfootforward (Oxford). 
CSO, 2011: Calculation of the average Irish house size in q2 of 2011. http://www.cso.ie/px/pxeirestat/statire/SelectVarVal/saveselections.asp. Last accessed $11^{\text {th }}$ November 2016.

DEFRA, 2011. Annex 6, DEFRA guidelines (Table 6K). Department for Environment, Food and Rural Affairs (London).

DEFRA, 2012. Guidelines for DEFRA/DECC's GHG Conversion Factors for Company Reporting. Department for Environment, Food and Rural Affairs (London).

Eirgrid, 2016. Available at http://www.eirgridgroup.com/how-the-gridworks/system-information/. Last accessed 9th April 2018.

ESRI, 2013. Advertising to boost energy efficiency: the Power of One campaign and natural gas consumption. The Economic and Social Research Institute (Dublin).

Foley W., 2006. Appraisal of The Sustainability Of Irish Settlements Using Metabolism Modelling. PhD thesis: College of Science, University of Limerick (Limerick).

Fowler, F. J., 2014. Survey Research Methods. Sage Publications (California).

GEN, 2015. Last accessed: http://gen.ecovillage.org/en/article/dimensionssustainability-0, accessed January 23rd, 2015.

Galli, A., 2015. On the rationale and policy usefulness of Ecological Footprint Accounting: The case of Morocco. Environmental Science \& Policy, 48, 210-224.

Galli, A., Iha, K., Halle, M., El Bilali, H., Grunewald, N., Eaton, D., Capone, R., Debs, P., \& Bottalico, F., 2017. Mediterranean countries' food consumption and sourcing patterns: An Ecological Footprint viewpoint. Science of the Total Environment, 578, 383-391.

GEN, 2018. Global Ecovillage Network. Available at: https://ecovillage.org/global-ecovillage-network/about-gen/. Last accessed 9/4/2018.

GFNSC, 2009. Ecological Footprint Standards 2009. Global Footprint Network (Oakland).

Hakanen, M., 2001. Finnish Local Ecological Footprints. Programme for Research and Documentation for a Sustainable Society (Oslo).

Kuzyk, L.W., 2012. The ecological footprint housing component: A geographic information system analysis. Ecological Indicators, 16, 31-39.

Leahy, E. and Lyons, S., 2009. Energy Use and Appliance Ownership in Ireland. The Economic and Social Research Institute (Dublin). 
Lejano, R.P., Tavares-Reager, J. and Berkes, F., 2013. Climate and narrative: Environmental knowledge in everyday life. Environmental Science and Policy, 31, 61-70.

Litfin, K.T., 2014. Ecovillages: Lessons for Sustainable Community. Polity Press (Cambridge).

Lin, T., Yu, Y., Bai, X., Feng, L. and Wang, J., 2013. Greenhouse Gas Emissions Accounting of Urban Residential Consumption: A Household Survey Based Approach. PLoS ONE 8(2): e55642. doi:10.1371/journal.pone.0055642.

Liu, Q., Cooper, G., Linge, N., Takruri, H. and Sowden, R., 2013. DEHEMS: Creating a Digital Environment for Large-Scale Energy Management at Homes. IEEE Transactions on Consumer Electronics, 59, 1, 62-69.

McLoughlin, P.J., 2015. Personal Communication with staff of Tipperary Energy Agency (Tipperary).

Oppenheim, A.N., 2000. Questionnaire Design, Interviewing and Attitude Measurement. Continuum (London).

Ryan B., 2003. Ecological Footprint Analysis; A comparison between a rural village and ecovillage footprint. MSc thesis, Dublin Institute of Technology (Dublin).

Ryan, B., 2004. Ecological footprint analysis: an Irish rural study. Irish Geography, $37,2,223-235$.

Ryan, P., 2006. Development of a consumption accounting model and scenario framework to examine materials flow through an Irish community as a tool for sustainable development through innovative material flow management. $\mathrm{PhD}$ thesis: College of Science, University of Limerick (Limerick).

Satterfield, T., Slovic, P. \& Gregory, R., 2000. Narrative valuation in a policy judgment context. Ecological Economics, 34, 315-331.

SEAI, 2008. Energy in the Residential Sector. SEAI (Dublin).

SEAI, 2013. Energy in the Residential Sector. SEAI (Dublin).

SEAI, 2015a:

http://www.seai.ie/Your_Business/Public_Sector/FAQ/Energy_Reporting_Overv iew/What_units_do_we_use_to_submit_energy_data_What_are_the_conversion_fa ctors_used_.html. Last accessed 9th April 2018.

SEAI, 2015b: http://www.seai.ie/Energy-Data-Portal/Emission_Factors/. Last accessed $11^{\text {th }}$ November 2016.

Slocum, N., 2003. Participatory Methods Toolkit A practitioner's manual. King Baudouin Foundation (New York). 
SPIL, 2007. The Village Ecological Charter, version 5. SPIL (Cloughjordan).

Sutcliffe, M., Hooper, P. and Howell, R., 2008. Can Eco-Footprinting Analysis Be Used Successfully to Encourage More Sustainable Behaviour at the Household Level? Sustainable Development, 16, 1, 1-16.

Van Vuuren, D.P. and Bouwman, L.F., 2005. Exploring past and future changes in the ecological footprint for world regions. Ecological Economics, 52, 5, 43-62.

Wackernagel, M., 1994. Ecological Footprint and Appropriated Carrying Capacity; a Tool for Planning Toward Sustainability. PhD thesis: School of Community and Regional Planning, The University of British Columbia (Canada).

Wilson, J. and Grant, J.L., 2009. Calculating ecological footprints at the municipal level: what is a reasonable approach for Canada? Local Environment, 14, 10, 963979.

WWF, 2005. Reducing Wales Footprint. A resource accounting tool for sustainable consumption. World Wildlife Fund (Gland, Switzerland).

WWF, 2014. Living Planet Report 2014: Species and spaces, people and places, WWF (Gland, Switzerland).

\section{Appendix}

Ecovillage EF Survey Questionnaire 